\title{
ZU ANTIKEN STÄDTEN WESTKILIKIENS
}

\author{
(angeregt und zusammengestellt von GERHARD HuBER)
}

I. KuRt Tomaschitz, Die epigraphische Evidenz westkilikischer Städte

II. Gerhard Huber, Weiteres zu Syedra

III. Leonhard ReIs, Die Typologie der kaiserzeitlichen Prägungen aus Syedra IV. Veronika Scheibelreiter, Ein mythologisches Mosaik aus Syedra/Nauloi

\section{VORBEMERKUNG}

Der hier vorgelegte Bericht ist eine Ergänzung zur Publikation „Syedra“ von G. Huber, Anzeiger der phil.-hist. Klasse der ÖAW 129 (1992 [1993]), 27-78, die den Stand der Erhebungen bis 1992 dokumentierte. Eine zusammenfassende Darstellung Syedras mit Literaturangaben ist dort gegeben.

Bei der Fortsetzung meiner baugeschichtlichen Untersuchungen hatte ich die Absicht, auch die Syedra benachbarten Plätze Hamaxia und Laërtes einzubeziehen und begleitend dazu die epigraphische und numismatische Evidenz zu den genannten Orten von altertumswissenschaftlicher Seite evaluieren zu lassen. Dieser ursprünglichen Planung entspricht der epigraphische Beitrag von Kurt Tomaschitz, während verschiedene unvorhersehbare Probleme sowohl beim baugeschichtlichen wie beim numismatischen Teil letztlich doch eine Beschränkung auf Syedra erzwangen. Im Sinne fächerübergreifender Arbeit werden Aussagen über:

- Inschriften

- Münzen

- Mosaiken

bezüglich Syedra, teils auch seiner Umgebung, von Fachkollegen erarbeitet und in dieser Publikationsreihe vorgelegt.

GERHARd HUBER 